\title{
Biliary obstruction caused by the liver fluke, Fasciola hepatica
}

\author{
Takuya Ishikawa MD PhD, Vanessa Meier-Stephenson MD PhD, Steven J. Heitman MD MSc
}

Competing interests: None declared.

This article has been peer reviewed.

The authors have obtained patient consent.

Correspondence to: Steven Heitman, steven.heitman@ucalgary.ca

CMAJ 2016. DOI:10.1503 /cmaj.150696
$\mathrm{A}$ 20-year-old previously healthy man presented to hospital with a two-day history of right upper quadrant pain and vomiting. Nine months earlier, he had immigrated to Canada from Sudan, but he had also lived in Djibouti and Ethiopia. Four months before he presented to hospital, he received a diagnosis of tuberculous lymphadenitis and a four-drug course of tuberculosis treatment was started. However, he was nonadherent after only two months of treatment. In addition, results from screening tests at that time showed evidence of schistosomiasis for which he was prescribed praziquantel.

On examination, he was alert and without jaundice or scleral icterus. He had right upper quadrant tenderness on abdominal examination, but there were no palpable masses. The remainder of his examination was unremarkable. Laboratory test results showed elevated liver enzymes (aspartate transaminase 133 [normal < 40] U/L, alanine transaminase 217 [normal < 41] U/L, alkaline phosphatase 166 [normal 38-126] U/L and $\gamma$-glutamyltransferase 459 [normal 8-61] U/L) and a normal total bilirubin. Transabdominal ultrasonography showed a distended gallbladder containing some debris (Appendix 1, available at www.cmaj.ca/lookup/suppl /doi:10.1503/cmaj.150696/-/DC1) and a prominent common bile duct with a transverse diame-

\section{KEY POINTS}

- Fascioliasis is an uncommon cause of biliary obstruction in North America; however, expanded world travel and immigration make it a global concern.

- Treatment should commence after the organism is identified; triclabendazole is first-line treatment for fascioliasis, but its availability is limited in Canada.

- Endoscopic retrograde cholangiopancreatography is a useful tool for clearing the biliary tree of dead and living liver flukes.

A video showing a liver fluke (Hepatica fasciola) emerging from the patient's common bile duct is available in Appendix 2, at www.cmaj.ca /lookup/suppl/doi:10.1503/cmaj.150696/-/DC2.

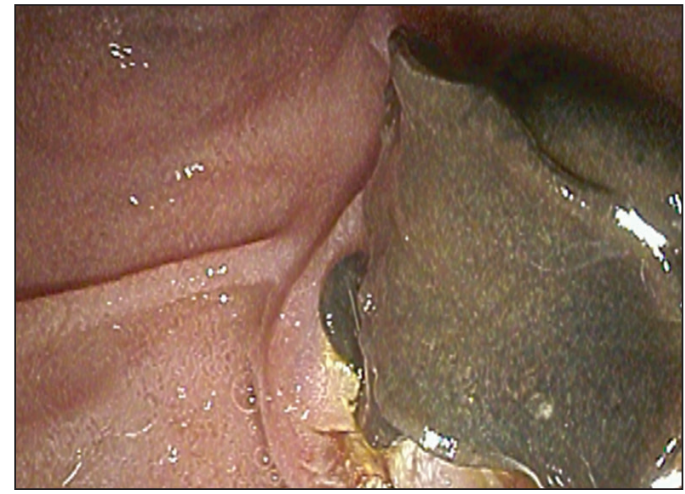

Figure 1: A flat, leaf-shaped, brown worm emerging from the common bile duct of a 20 -year-old man with abdominal pain.

ter of $1.1 \mathrm{~cm}$. A computed tomography scan of the abdomen also showed prominence of the common bile duct, but no calcified stone was identified (Appendix 1). A hepatobiliary iminodiacetic acid scan suggested distal obstruction in the common bile duct. Endoscopic retrograde cholangiopancreatography was performed and showed a normal major papilla without any trauma or inflammation. The cholangiogram showed an irregular defect in the common bile duct (Appendix 1). A sphincterotomy and sweep of the common bile duct with a balloon showed a living, brown, leaf-shaped flat worm (Figure 1; Appendix 2, video available at www.cmaj.ca/ lookup/suppl/doi:10.1503/cmaj.150696/-/DC2). The organism was removed using a net basket, and the gross specimen was sent to pathology (Figure 2A). Praziquantel $(25 \mathrm{mg} / \mathrm{kg}$, three times daily for two days) was prescribed after the procedure at the recommendation of the infectious disease service. The patient was discharged without complications, and he had immediate symptomatic relief after endoscopic retrograde cholangiopancreatography. The specimen was subsequently identified as Fasciola hepatica (Figure 2) and treatment with triclabendazole was started. On follow-up examination three weeks later, he remained asymptomatic and test results showed that his liver enzyme levels were normal. 


\section{Discussion}

Helminthic infestation of the hepatobiliary system can result from roundworms, tapeworms and flat worms, such as flukes. These parasites differ in endemicity, clinical presentation and treatment; therefore, a thorough travel and exposure history is critical for establishing a diagnosis and management plan. ${ }^{1}$ Fasciola hepatica is endemic to South America, North Africa, Asia and Europe. The organism is typically found in areas where cattle or sheep are grazing within proximity to a water source, because both these larger mammals and a specific snail host are needed for the fluke to complete its life cycle. ${ }^{2,3}$ Although fascioliasis is far more common in developing countries, this case shows that para- sitic infectious disease has become a global concern because of expanded world travel and immigration.

Different species of liver flukes have predilictions for either the intrahepatic or extrahepatic biliary tree. Clonorchis and Opisthorchis species prefer the intrahepatic biliary tree, whereas Fasciola hepatica and Fasciola gigantica prefer the extrahepatic bile ducts. In addition, the roundworm Ascaris also favours the extrahepatic biliary tree following its aberrant migration from the small intestine. ${ }^{1}$ The larvae of most flukes migrate retrograde up the biliary tree before settling; however, Fasciola species prefer to tunnel through the bowel wall and may spend up to 24 hours in the peritoneal cavity before locating the liver and penetrating the

\begin{tabular}{|c|c|}
\hline Disease entity & Characteristics \\
\hline Biliary stones (most common) & Abdominal pain, elevated liver enzyme levels and dilated biliary tree \\
\hline \multicolumn{2}{|l|}{ Benign stricture } \\
\hline Primary sclerosing cholangitis & $\begin{array}{l}\text { Asymptomatic or symptoms such as fatigue and pruritus; usually associated with colitis; } \\
\text { elevated liver enzyme levels; multifocal stricturing causing a beaded appearance in the } \\
\text { biliary tree }\end{array}$ \\
\hline $\begin{array}{l}\text { Chronic pancreatitis with stricturing } \\
\text { of the distal bile duct }\end{array}$ & $\begin{array}{l}\text { Abdominal pain and elevated liver enzyme levels; symptomatic obstruction of the bile duct } \\
\text { caused by inflammation and fibrosis in the head of the pancreas, or a pseudocyst }\end{array}$ \\
\hline \multicolumn{2}{|l|}{ Malignant stricture } \\
\hline Pancreas, ampulla of Vater, bile duct & Painless jaundice and constitutional symptoms; dilated biliary tree \\
\hline Choledochal cyst & $\begin{array}{l}\text { Congenital anomaly; presents as recurrent abdominal pain and cholangitis; isolated or } \\
\text { combined dilatations of the extra- and intrahepatic biliary trees }\end{array}$ \\
\hline Drug reaction & $\begin{array}{l}\text { May mimic viral hepatitis or biliary tract disease; rash, arthralgia and eosinophilia can be } \\
\text { clues }\end{array}$ \\
\hline \multicolumn{2}{|l|}{ Infection } \\
\hline \multicolumn{2}{|l|}{ Bacterial/mycobacterial } \\
\hline Abscess & Fevers, chills, rigors; obstructive symptoms \\
\hline Tuberculoma & Appropriate exposure history \\
\hline \multicolumn{2}{|l|}{ Parasitic } \\
\hline \multicolumn{2}{|l|}{ Ascariasis } \\
\hline Ascaris lumbricoides & $\begin{array}{l}\text { Endemic in Asia, Africa and South Africa; resides in the small intestine, but may migrate } \\
\text { into aberrant sites, such as the bile duct, through the papilla causing biliary colic and } \\
\text { obstructive jaundice }\end{array}$ \\
\hline \multicolumn{2}{|l|}{ Liver flukes } \\
\hline $\begin{array}{l}\text { Fascioliasis (Fasciola hepatica, } \\
\text { Fasciola gigantica) }\end{array}$ & $\begin{array}{l}\text { Endemic in South America, North Africa, Asia and Europe; biliary obstruction, cholangitis, } \\
\text { cirrhosis }\end{array}$ \\
\hline \multicolumn{2}{|l|}{ Opisthorchiasis } \\
\hline Opisthorchis viverrini & Endemic in Thailand, Laos, Cambodia and Vietnam; cholangitis, cholangiocarcinoma \\
\hline Opisthorchis felinus & $\begin{array}{l}\text { Endemic in Russia, Siberia, Ukraine and Kazakhstan; suppurative cholangitis and liver } \\
\text { abscess }\end{array}$ \\
\hline \multicolumn{2}{|l|}{ Clonorchiasis } \\
\hline Clonorchis sinensis & $\begin{array}{l}\text { Endemic in Northeast China, southern Korea, Japan, Taiwan, northern Vietnam and far east } \\
\text { Russia; gallbladder and intrahepatic duct stone, recurrent pyogenic cholangitis, } \\
\text { cholecystitis, liver abscess }\end{array}$ \\
\hline
\end{tabular}




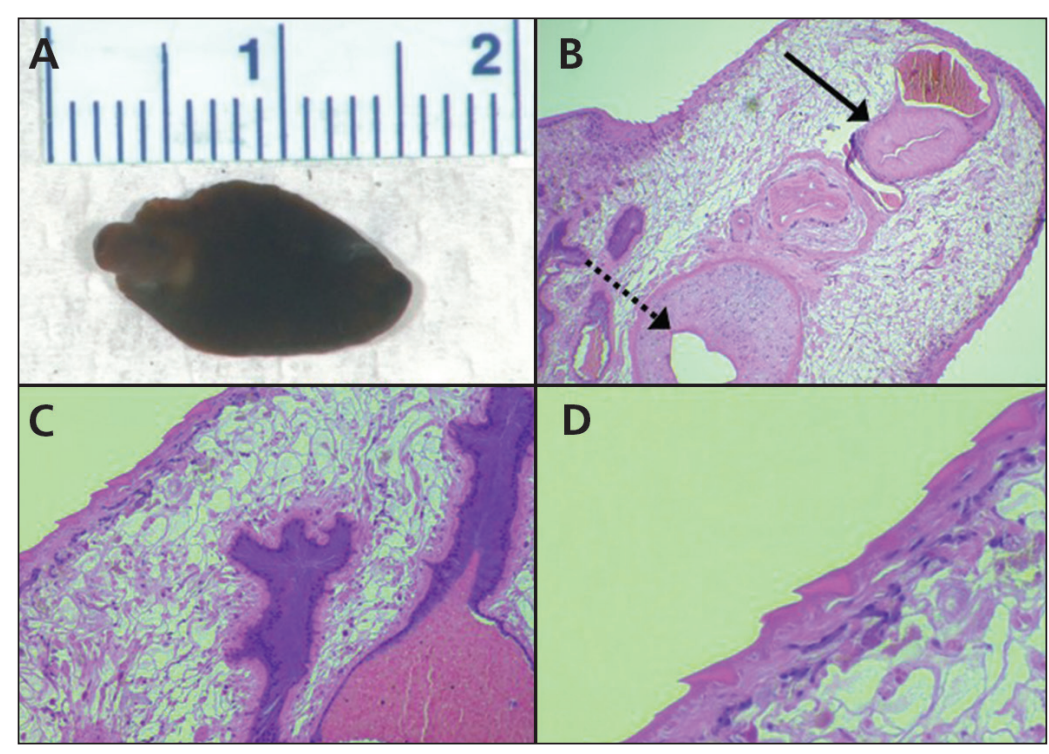

Figure 2: Photograph of the brown, leaf-shaped parasite $\left(1.5 \times 0.8 \times 0.2 \mathrm{~cm}^{3}\right.$ in size) extracted from the common bile duct of a 20-year-old man (A). Photomicrographs of the specimen showing the oral (black arrow) and ventral (black broken arrow) suckers (original magnification $\times 40)(B)$, branching intestines (original magnification $\times 100)(C)$ and spiked integument (original magnification $\times 200)(D)$. Using the patient's immigration history from North Africa, the specimen was identified as the liver fluke, Fasciola hepatica. The size and lack of identifiable eggs indicate an immature adult form of the parasite.

liver capsule into the parenchyma (hepatic stage). ${ }^{2}$ Once the Fasciola species is in the liver, it tunnels through the parenchyma to the biliary ducts and matures within the biliary system (biliary stage) ${ }^{4}$ While the fluke is tunneling, a peripheral blood smear often shows eosinophilia, which can be a clue to the presence of a parasitic infection.

Once the fluke is in the biliary system, test results will often show elevated cholestatic liver enzyme levels, and in endemic areas, this laboratory finding raises suspicion of the diagnosis. ${ }^{5}$ In nonendemic areas, elevated cholestatic liver enzyme levels associated with abdominal pain usually leads to workup for gallstone disease, which was our primary differential diagnosis (Box 1). ${ }^{6}$ Indeed, the patient presented with right upper pain, elevated liver enzyme levels and a dilated biliary tree, typical of a common bile duct stone.

Infections caused by Fasciola species can be diagnosed by microscopic stool examination; however, immunologic techniques, such as enzyme-linked immunosorbent assay, play a more important role because they have $100 \%$ sensitivity and $97.8 \%$ specificity for fascioliasis. ${ }^{7}$ In this case, the stool analysis was negative for ova and parasites. Pathologically, liver flukes can be distinguished from one another based on their size, internal organ arrangement and integument features (Figure 2). ${ }^{8}$

Most liver fluke infections are treated with praziquantel. ${ }^{9}$ Praziquantel has a broad spectrum of activity and is the drug of choice for various trematodiasis, such as clonorchiasis, opisthorchiasis, paragonimiasis and intestinal fluke infections. However, fascioliasis responds poorly to praziquantel, ${ }^{10}$ and, thus, our initial choice of treatment was suboptimal. Triclabendazole is recommended for Fasciola infections. ${ }^{3}$ However, it is currently approved in only a few countries (e.g., Egypt and Peru) ${ }^{9}$ for use as a treatment for fascioliasis in humans. In Canada, it is necessary to make a request to Health Canada's Special Access Programme for Drugs to obtain triclabendazole (www.hc-sc.gc.ca/dhp-mps/ acces/drugs-drogues/index-eng.php).

Follow-up examination should ensure resolution of clinical symptoms, laboratory abnormalities (including eosinophilia, elevated liver enzyme levels and serologic titres) and radiologic findings (ultrasonographic biliary tract abnormalities). ${ }^{2}$ Endoscopic clearance of the biliary tree may also be necessary in some instances, because of the risk of biliary obstruction and its related complications, such as cholangitis and pancreatitis, that result from the presence of dead flukes after drug treatment. ${ }^{2}$

\section{References}

1. Pockros PJ, Capozza TA. Helminthic infections of the liver. Curr Infect Dis Rep 2005;7:61-70.

2. Sezgin O, Altintas E, Disibeyaz S, et al. Hepatobiliary fascioliasis: clinical and radiologic features and endoscopic management. J Clin Gastroenterol 2004;38:285-91.

3. Parasites - Fascioliasis (Fasciola Infection). Atlanta: Centers for Disease Control and Prevention; 2013. Available: www.cdc .gov/parasites/fasciola/biology.html (accessed 2015 Oct. 26).

4. Lim JH, Mairiang E, Ahn GH. Biliary parasitic diseases including clonorchiasis, opisthorchiasis and fascioliasis. Abdom Imaging 2008;33:157-65.

5. Marcos LA, Terashima A, Gotuzzo E. Update on hepatobiliary flukes: fascioliasis, opisthorchiasis and clonorchiasis. Curr Opin Infect Dis 2008;21:523-30.

6. Assy N, Jacob G, Spira G, et al. Diagnostic approach to patients with cholestatic jaundice. World J Gastroenterol 1999;5:252-62.

7. Al Qurashi H, Masoodi I, Al Sofiyani M, et al. Biliary fascioliasis - an uncommon cause of recurrent biliary colics: report of a case and brief review. Ger Med Sci 2012;10:Doc10.

8. Bennett CE. Scanning electron microscopy of Fasciola hepatica $\mathrm{L}$. during growth and maturation in the mouse. J Parasitol 1975;61:892-8.

9. Keiser J, Utzinger J. Chemotherapy for major food-borne trematodes: a review. Expert Opin Pharmacother 2004;5:1711-26.

10. Patrick DM, Isaac-Renton J. Praziquantel failure in the treatment of Fasciola hepatica. Can J Infect Dis 1992;3:33-6.

Affiliations: Division of Gastroenterology (Ishikawa, Heitman), Division of Infectious Disease (Meier-Stephenson), Department of Medicine, University of Calgary, Calgary, Alta.

Contributors: Takuya Ishikawa performed the procedure. Vanessa Meier-Stephenson led the discussion of the pathology and epidemiology. All of the authors drafted the article, reviewed it critically for intellectual content, approved the final version to be published and agreed to act as guarantors of the work.

Acknowledgements: The authors are grateful to Sydney Bass for supervising the procedure. The authors also thank Stephen Vaughan and Dan Gregson for their involvement in the diagnosis and input in the management of the case. 